\title{
A longitudinal follow-up of COVID-19 patients in the convalescent phase showed recovery in radiological results, the dynamics of lymphocytes, and a decrease in the level of IgG antibody: a single-centre, observational study
}

\author{
Ziqi Wang ${ }^{1}$, Li Yang ${ }^{1}$, Yi Chen ${ }^{2}$, Zhiwei Xu' ${ }^{2}$, Hui Wang ${ }^{3,4}$, Xiaoju Zhang ${ }^{1}$ \\ ${ }^{1}$ Department of Respiratory and Critical Care Medicine, Zhengzhou University People's Hospital, Henan Provincial People's Hospital, Zhengzhou, \\ China; ${ }^{2}$ Clinical Research Service Centre, Henan Provincial People's Hospital, Zhengzhou University People's Hospital, Zhengzhou, China; \\ ${ }^{3}$ Xinxiang Medical School, Xinxiang, China; ${ }^{4}$ Henan Provincial People's Hospital, Zhengzhou, China \\ Contributions: (I) Conception and design: X Zhang, Z Wang; (II) Administrative support: X Zhang, Z Xu; (III) Provision of study materials or \\ patients: X Zhang, Z Wang; (IV) Collection and assembly of data: Z Wang, L Yang, Y Chen, H Wang; (V) Data analysis and interpretation: X Zhang, \\ Z Xu; (VI) Manuscript writing: All authors; (VII) Final approval of manuscript: All authors. \\ Correspondence to: Xiaoju Zhang, PhD. No. 7 Weiwu Road, Zhengzhou, China. Email: 15837101166@163.com.
}

Background: Given the high prevalence of coronavirus disease 2019 (COVID-19) globally, and the increased number of patients being discharged, it is necessary to understand the health consequences of COVID-19 to formulate and manage public policy concerning convalescent patients.

Methods: A longitudinal follow-up investigation of 25 patients from a tertiary hospital in Henan provincial was conducted 8 weeks after discharge. Of these patients, 15 attended a second follow-up appointment 8 weeks after that. A throat swab reverse transcription-polymerase chain reaction (RT-PCR) analysis for SARS-CoV-2 and chest computerized tomography (CT) scans were implemented at the first follow-up appointment, and a total of 40 blood samples (25 from the first and 15 from the second follow-up appointment) were collected. Patients' levels of Immunoglobulin G (IgG) antibody against S-Receptor binding domain (S-RBD) and Nucleocapsid Protein (NP) of SARS-CoV-2 and the subpopulation of lymphocytes were evaluated using an enzyme-linked immunoassay (ELISA) test and flow cytometry, respectively.

Results: At the first follow-up appointment, 10 of the 25 patients (40.0\%) showed complete radiological resolution. Of these patients, $80.0 \%$ were classified as moderate, and $80.0 \%$ were younger (those whose age was $\leq$ the median age of all the patients). The predominant patterns of abnormalities included an irregular line $(12 / 25,48.0 \%)$, ground-glass opacity (GGO) (44.0\%), and multiple GGOs (28.0\%). At the first followup appointment, $40.0 \%(10 / 25)$ of patients still had lymphopenia. Of the 15 patients who were followed-up with twice, the ratio of lymphopenia was $80 \%(12 / 15), 60.0 \%(9 / 15)$, and $46.7 \%(7 / 15)$ at 0,8 , and 16 weeks after discharge, respectively. This was mainly due to a decrease in the cluster of differentiation (CD) $4+\mathrm{T}$ lymphocyte, which was observed in 60\% (9/15), 60\% (9/15), and 46.7\% (7/15) of total patients at 0,8 , and 16 weeks after discharge, respectively. All of the patients were S-RBD and NP IgG antibody positive at the first follow-up appointment. $40.0 \%(6 / 15)$ and $66.7 \%$ (10/15) of patients showed a decrease over $50.0 \%$ in the level of NP and S-RBD IgG antibodies, respectively, at the second follow-up appointment. The NP and S-RBD IgG antibodies' levels declined to $44.6 \%(\mathrm{P}=0.044)$ and $28.1 \%(\mathrm{P}=0.18)$, respectively. 0 and $26.7 \%$ (4/15) of patients turned from NP and S-RBD IgG antibody positive to negative, respectively.

Conclusions: About half of the patients still showed at least 1 abnormality in chest CT scans 8 weeks after discharge and lymphopenia 16 weeks after discharge. The level of the IgG antibody had declined by the follow-up appointment. Notably, the S-RBD IgG antibody declined more dramatically than that of NP. These results may have implications in the making of policies related to disease prevention, the long-term management of discharged patients, and vaccines' development. 
Keywords: Coronavirus disease 2019 (COVID-19); convalescent phase; follow-up

Submitted Oct 02, 2020. Accepted for publication Apr 07, 2021.

doi: $10.21037 /$ jtd-20-3011

View this article at: http://dx.doi.org/10.21037/jtd-20-3011

\section{Introduction}

Coronavirus disease 2019 (COVID-19), a disease caused by Severe Atypical Respiratory Syndrome-Coronavirus-2 (SARS-CoV-2), has now become a pandemic and continues to rage globally (1). As of February 8th, 2021, over 100 million confirmed cases of COVID-19 and over 2 million deaths globally have occurred (2).

Extensive research has been undertaken to characterize patients' epidemiological and clinical characteristics with COVID-19 (3-6). It has been widely reported that COVID-19 is underlined by complex crosstalk between SARS-CoV-2 and the host immune system (7). Most patients with COVID-19 present with a decrease (either in count or ratio) of lymphocytes, which is one of the criteria for a diagnosis of COVID-19 (8) and which is thought to be correlated with the severity of the disease (3). Immune dysregulation has a destructive effect. However, in most cases, hosts generate cellular and humoral immunity to clear the virus, which finally leads to the convalescent phase. There is a different level of protection against the same pathogen that is at least partly reflected by the level of Immunoglobulin $\mathrm{G}$ (IgG) antibody.

With more and more patients discharged, several studies have sought to evaluate the status of COVID-19 patients in the convalescent phase from clinical, virological, and radiological perspectives (9-11). However, to date, very little is known about how the immune system recovers from the disease. Notably, lung injury caused by the virus is one of the main clinical manifestations. It significantly affects prognosis (12), and radiologically it manifests as multiple abnormalities, such as multifocal ground-glass opacity (GGO) and consolidation. The dynamic process [as shown in chest computerized tomography (CT) scans] from the hospitalization phase to the convalescence phase is of great value to understand the recovery process of lung injury caused by SARS-CoV-2, which remains under-reported (11). We performed a longitudinal follow-up investigation of 25 convalescent patients from a tertiary hospital in Henan province, China, 8 weeks after discharge. Of these 25 patients, 15 were followed-up with again 8 weeks after that. We mainly focused on the radiological characteristics, the dynamics of the lymphocytes subpopulation, and the $\mathrm{IgG}$ level against SARS-CoV-2 to understand the status of convalescent patients and the long-term effects of SARS$\mathrm{CoV}-2$ infection.

We present the following article in accordance with the STROBE reporting checklist (available at http://dx.doi. org/10.21037/jtd-20-3011).

\section{Methods}

\section{Study design and participants}

Patients who had recovered from COVID-19 were enrolled at Henan Provincial People's Hospital. They were diagnosed and treated according to the Diagnosis and Treatment Plan for Novel Coronavirus Pneumonia Cases (Provisional) (5th Edition) published by the National Health Commission of the People's Republic of China (8) between the January 15th, 2020 to February 10th, 2020, and discharged between February 1st, 2020 and February 25th, 2020. The first follow-up appointments were conducted between April 1st-27th, 2020, and the second follow-up appointments were conducted between June 1st-26th, 2020.

The follow-up appointments were conducted by trained medical staff via telephone, and scheduled according to the order of discharge date as recorded on the medical records. An appointment 3 days in advance or a delay of 3 days was deemed acceptable. At the first follow-up appointment, a reverse transcription-polymerase chain reaction (RT-PCR) analysis for SARS-CoV-2 was conducted, chest CT images were taken, and lymphocytes' subpopulation and the level of the IgG antibody were assessed. At the second followup appointment, the subpopulation of lymphocytes and the IgG antibody level were assessed. Any patients that could not attend the second follow-up appointment were excluded from the paired variables test. Figure 1 shows the study design.

\section{Criteria for severity grading}

Using the Diagnosis and Treatment Plan for Novel Coronavirus Pneumonia Cases (Provisional) (5th Edition), severity was 


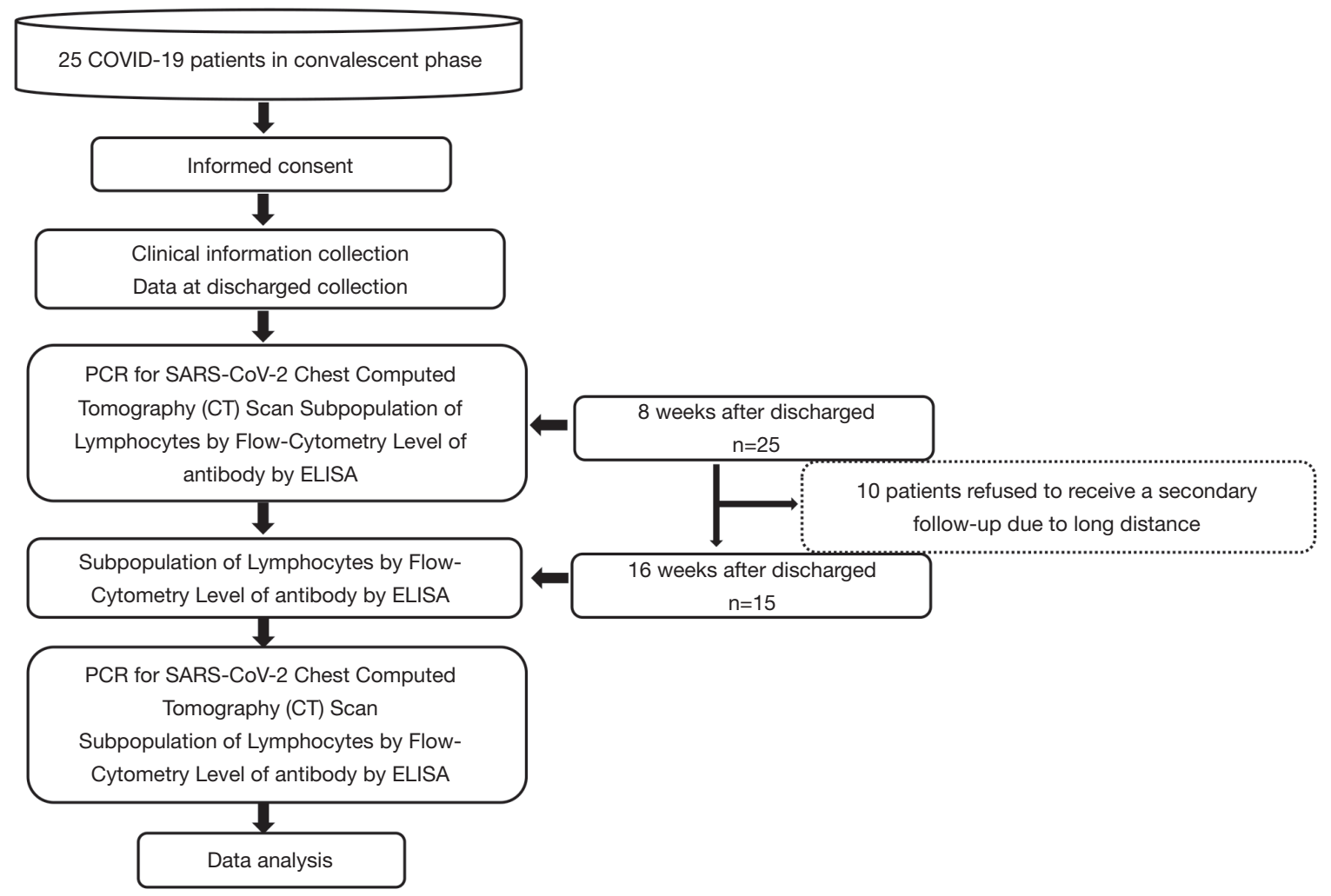

Figure 1 Flow diagram of the study design.

graded as follows:

(I) Mild: the clinical symptoms were mild, and the imaging findings showed no pneumonia;

(II) Moderate: the clinical symptoms included fever, respiratory tract infection and other symptoms, and imaging manifestations of pneumonia;

(III) Severe: the clinical symptoms included any of the following: (i) respiratory distress, as demonstrated by a respiratory rate $(\mathrm{RR}) \geq 30$ beats $/ \mathrm{min}$; (ii) at rest, oxygen saturation was less than or equal to 93\%; and/or (iii) partial pressure of oxygen $\left(\mathrm{PaO}_{2}\right) /$ Fraction of Inspired Oxygen $\left(\mathrm{FiO}_{2}\right) \leq 300 \mathrm{mmHg}$ $(1 \mathrm{mmHg}=0.133 \mathrm{kPa})$; or

(IV) Critical: one of the following conditions was met: (i) respiratory failure and mechanical ventilation required; (ii) shock; or (iii) other organ failure requiring intensive care unit monitoring and treatment.

\section{Data collection and sample measurement}

Patients' epidemiological, demographic information, and chest CT images were retrieved from electronic medical records. A positive RT-PCR result confirmed SARS-CoV-2 infection for SARS-CoV-2. Samples were obtained by swabbing the oropharyngeal mucosa of all individuals. The subpopulation of lymphocytes was evaluated using an ACEA QuadriTEST $^{\circledast}$ (cat. no. 892009) kit [CD3+ fluorescein isothiocyanate (FITC)/CD16 + CD56 PE/CD45 PerCP/ CD19 APC] following the manufacturer's standard procedure. First, $2 \mathrm{~mL}$ of peripheral venous blood was drawn from each patient into an ethylenediaminetetraacetic acid (EDTA) tube. Second, $20 \mu \mathrm{L}$ antibody reagent from an ACEA QuadriTEST ${ }^{\circledR}$ kit was added to a $5 \mathrm{~mL}$ roundbottom tube. Third, $50 \mu \mathrm{L}$ blood was then added, and incubated at room temperature $\left(18-25^{\circ} \mathrm{C}\right)$ for $15 \mathrm{~min}$ after $5 \mathrm{sec}$ vortex. Fourth, $450 \mu \mathrm{L} 1 \times$ dilution hemolysin (Agilent) was added to the tube, which was incubated at room temperature $\left(18-25^{\circ} \mathrm{C}\right)$ for 15 min after $5 \mathrm{sec}$ vortex. Finally, an Agilent NovoCyte flow-cytometry machine and NovoExpressed software were used to analyze the prepared sample's lymphocytes population.

An ELISA test was used to determine the level of the IgG antibody. Plates were coated by recombinant S-receptor 
binding domain (S-RBD; Sino Biologic, cat. No. $40592-$ V08B) and N protein (Sino Biologic, cat.no 40588-V08B) at a dilution of $2 \mu \mathrm{g} / \mathrm{mL}$, and then incubated at 4 centigrade overnight, and blocked by skimmed milk. The sera of patients and 10 healthy controls were diluted $(1: 1,000)$ and added to the prepared plates. Anti-human IgG HRPlabeled antibody was used as the secondary antibody, and 3, 3', 5, 5'-Tetramethylbenzidine was used for color rendering. The absorbance at $450 \mathrm{~nm}$ was determined. To avoid any batch effect between different plates, 12 wells of each plate were used as blank controls. The procedure was the same, except the serum was replaced with $100 \mu \mathrm{L}$ PBS. The blank controls' values were compared to different plates to determine if there was a batch effect. Three duplicates for each sample were set, and the mean OD450 nm value was used. The positive cut-off value was 0.60 for the S-RBD antibody and 0.48 for the Nucleocapsid Protein (NP) antibody, which was defined as twice the mean value of healthy controls. The OD450 nm value of each patient minus the cut-off value was defined as OD450 nm (adjusted), and an OD450 nm (adjusted) larger than 0 was considered positive.

\section{CT interpretation}

Two experienced radiologists (with 5 and 15 years of experience, respectively) reviewed patients' chest CT scans blindly and independently. All of the images were viewed with both lung (width, 1,600 HU; level, -600 HU) and mediastinal (width, $350 \mathrm{HU}$; level, $40 \mathrm{HU}$ ) settings. The 2 radiologists discussed any inconsistent results, and a consensus was reached. The COVID-19 Reporting and Data System (CO-RADS) scoring system (13) was used to evaluate the extent of pulmonary involvement. Notably, CO-RADS 6 was excluded, as according to the original definition of CO-RADS, which was not suitable for the current study, all patients who are RT-PCR positive for SARS-CoV-2 should be classified as CO-RADS 6.

\section{Statistical analysis}

Patients those whose age was $\leq$ the median age of all the patients [ 48 years old (y/o) for the first follow-up and $45 \mathrm{y} / \mathrm{o}$ for the second one] were defined as younger patients, and those whose age was $>$ the median age of all the patients were defined as older. The continuous variables were expressed as the median [range, mean \pm standard deviation (SD)]. The categorical variables were expressed as $\mathrm{n}(\%)$.
The student's $t$-test was used to compare the continuous variables. Fisher's exact test was used to compare categorical variables. Wilcox's test was used to compare the paired variables. A 2-tailed $\mathrm{P}$ value was used, and a value $<0.05$ was considered statistically significant. All of the statistics analyses and figure drawings were performed with $\mathrm{R}$ software v. 3.6.0 and Prism (GraphPad software) version 8.3.1.

\section{Patient and public involvement}

The study was conducted in accordance with the Declaration of Helsinki (as revised in 2013). The Ethics Committee of Henan Provincial People's Hospital approved this research study (2020 Ethical Approval No. 68), and the informed consent of all patients was obtained.

\section{Results}

\section{Demographic characteristics}

Twenty-five patients with a median age of 43 (18-58, $41.4 \pm 13.15)$ were followed-up 8 weeks after discharge. Forty-eight percent of the patients were female. Concerning severity level, $14(53.8 \%), 10(38.5 \%)$, and 1 (3.8\%) were classified as having moderate, severe, and critical COVID-19, respectively. The median duration of viral shedding (defined as the interval of the first and last time of positive RT-PCR for SARS-CoV-2) was 11.0 days (6-27, $12.8 \pm 5.21)$. Six $(24.0 \%), 3(12.0 \%)$, and $2(8.0 \%)$ patients had underlying hypertension, diabetes and cardiovascular diseases, respectively (see Table 1). Symptoms on admission included fever $(96.0 \%)$, a cough $(60.0 \%)$, sputum $(32.0 \%)$, sore throat $(16.0 \%)$, and fatigue $(4.0 \%)$ (see Table 2). Of the 25 patients, 15 had a median age of $43(19-58,43.9 \pm 12.99)$ and attended a second follow-up appointment 16 weeks after discharge for an antibody evaluation and examined the subpopulation lymphocytes (see Table 1). The remaining 10 patients refused to attend a second follow-up appointment due to the long distance that they would be required to travel.

\section{Virological results, self-reported symptoms, and radiological results}

8 weeks after discharge, a throat swab sample for the RTPCR analysis was taken from all patients for open reading frame 1 (ORF1) a, ORF1b, E, and the $N$ gene of SARS- 
Table 1 Clinical and epidemiological characteristics of patients followed-up

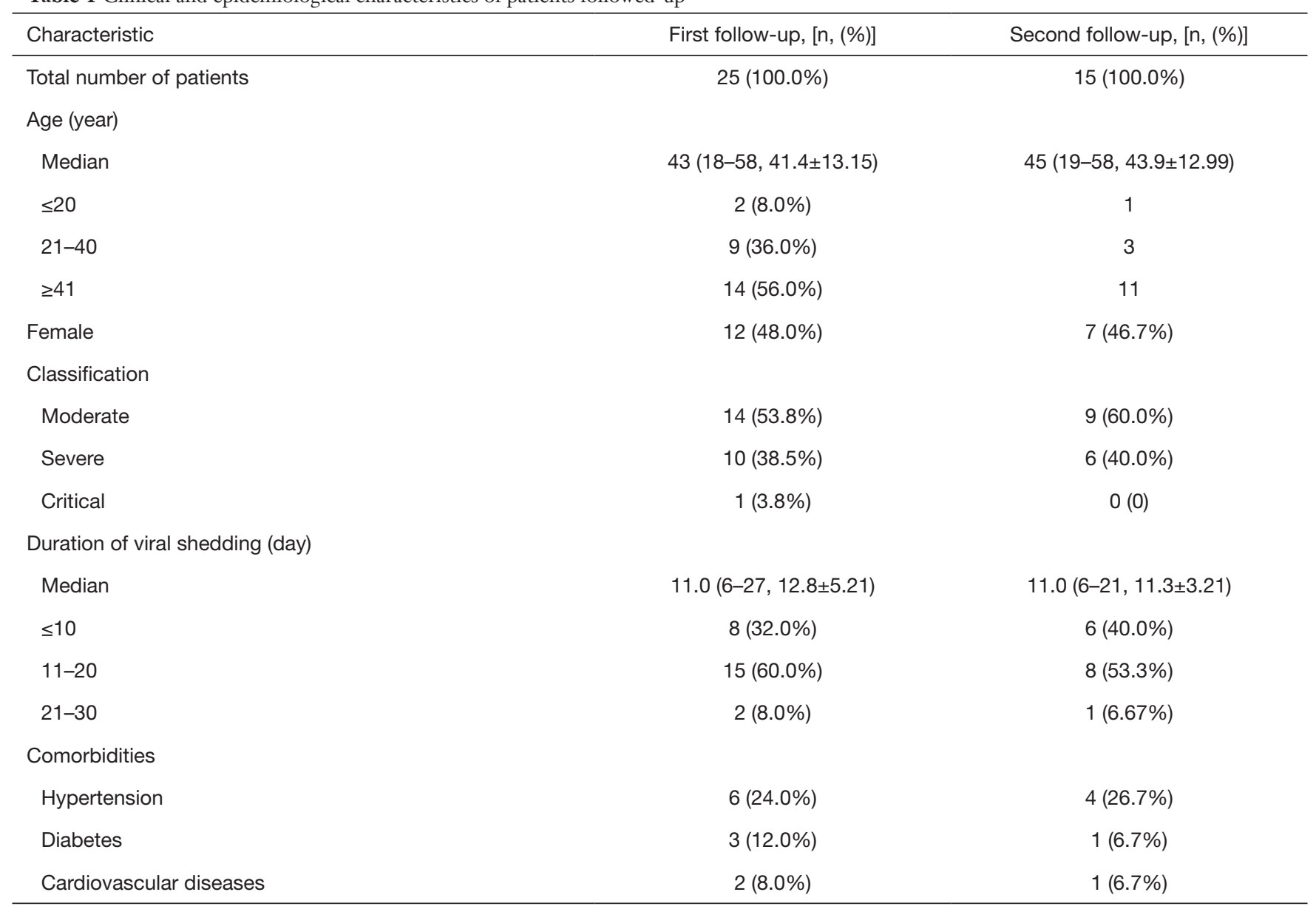

Table 2 Self-reported symptoms at different time points

\begin{tabular}{lcccc}
\hline Symptom & $\begin{array}{c}\text { Symptoms on admission [n } \\
(\%)] n=25\end{array}$ & $\begin{array}{c}\text { Symptoms at discharge [n } \\
(\%)] n=25\end{array}$ & $\begin{array}{c}\text { Symptoms at first follow-up [n } \\
(\%)] n=25\end{array}$ & $\begin{array}{c}\text { Symptoms at second } \\
\text { follow-up [n (\%)], } \mathrm{n}=15\end{array}$ \\
\hline Fever & $24(96.0 \%)$ & $0(0)$ & $0(0)$ \\
Cough & $15(60.0 \%)$ & $5(20.0 \%)$ & $4(16.0 \%)$ \\
Sputum & $8(32.0 \%)$ & $0(0)$ & $0(0)$ & $0(0)$ \\
Shortness of breath & $4(16.0 \%)$ & $0(0)$ & $0(0)$ & $0(0)$ \\
Sore throat & $1(4.0 \%)$ & $0(0)$ & $0(0)$ & $0(0)$ \\
Fatigue & $4(16.0 \%)$ & $0(0)$ & $1(4.0 \%)$ & $1(6.7 \%)$ \\
Ache in major joint & $0(0)$ & $0(0)$ & & 0 \\
\hline
\end{tabular}

$\mathrm{CoV}-2$, and no positive results were found. Four (16.0\%) patients reported the symptom of a cough, and 1 patient $(4.0 \%)$ reported an ache in a major joint (the right knee) at their first follow-up appointments. These patients complained of the same symptoms at their second follow-up appointments (see Table 2).

All of the patients received chest CT scans 8 weeks after discharge. Forty percent (10/25) of patients, mainly patients 
classified as moderate (80.0\%) and younger patients (80.0\%), showed complete radiological resolution. The CO-RADS score variation showed that the percentage of CO-RADS 1

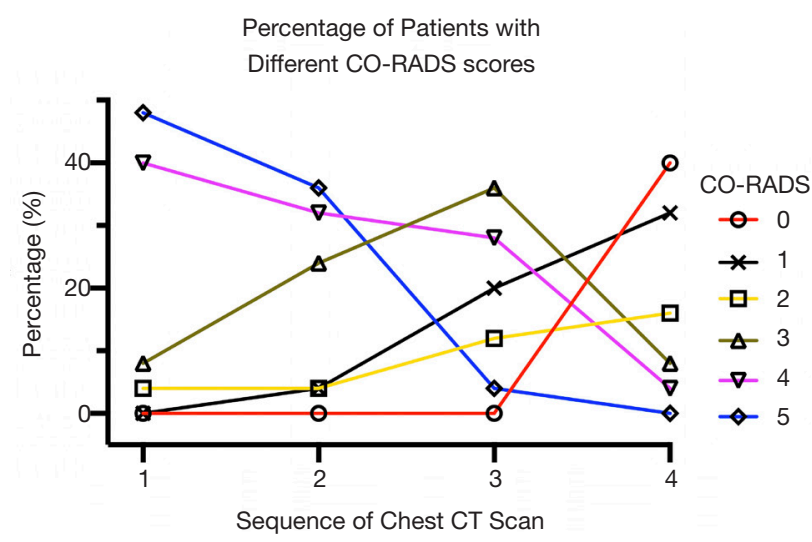

Figure 2 The kinetic of CO-RADS scoring at different time points. CO-RADS, COVID-19 Reporting and Data System. and 2 patients increased, but the percentage of CO-RADS 4 and 5 patients decreased (see Figure 2). The results showed the radiological dynamics from symptom onset to early convalescence. The predominant patterns of abnormalities observed at the first follow-up appointment included an irregular line $(12 / 25,48.0 \%$ ) (see Figure 3), GGO (44.0\%), and multiple GGOs (28.0\%) (see Figure 4). Other abnormalities included air bronchogram (24.0\%), local pleural thickening $(20.0 \%)$, interlobular septal thickening (12.0\%), and a subpleural line (12.0\%) (see Table 3). Except for a crazy-paving pattern, which disappeared during hospitalization, the positive count of all abnormalities decreased by the time of the first follow-up appointment (see Figure 5).

Eight weeks after discharge, taking age and severity into consideration, the results showed that younger $(\mathrm{P}=0.015)$ patients had a higher chance of being completely radiologically recovered than older patients. The same was observed in patients with various grades, but the results
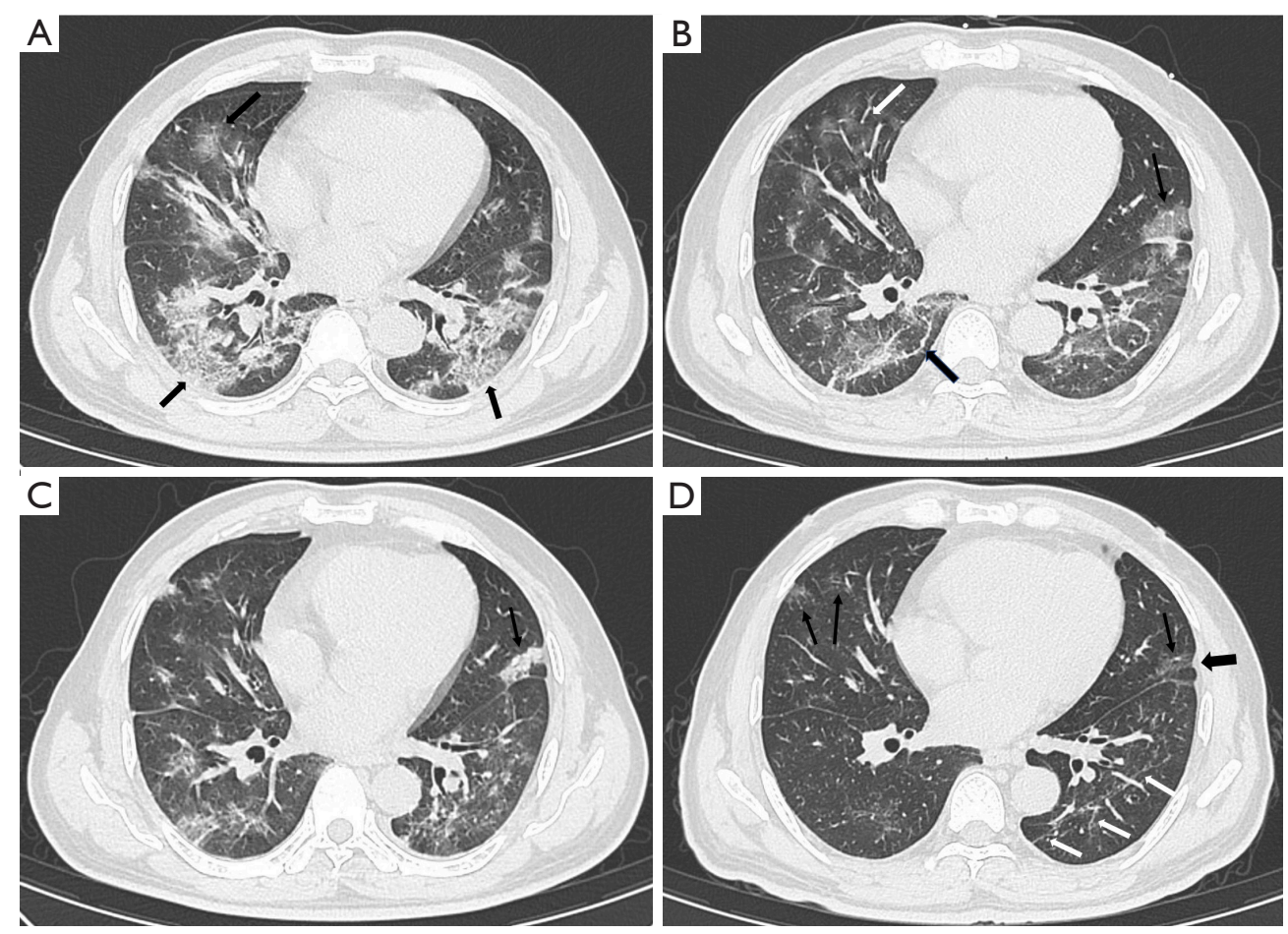

Figure 3 Serial chest CT scans of a 48-year-old female were graded as severe. (A) The scan obtained at the onset of symptoms showed GGO (thin arrow) with a "crazy-paving" pattern and air bronchogram (black arrow). (B) The scan obtained 7 days after the onset of symptoms showed evolution to consolidation (white arrow), and a mixture of GGO and consolidation (thin arrow) with increased density and decreased extension. (C) The scan obtained at discharge showed a mild decrease in extension than previous scans and minimal absorption; an air bronchogram was also observed (black arrow). (D) The scan at 8 weeks after discharge showed the evident absorption of previous abnormalities and multiple GGOs (white arrows) of decreased density and increased extension. CT, computerized tomography; GGO, ground-glass opacity. 

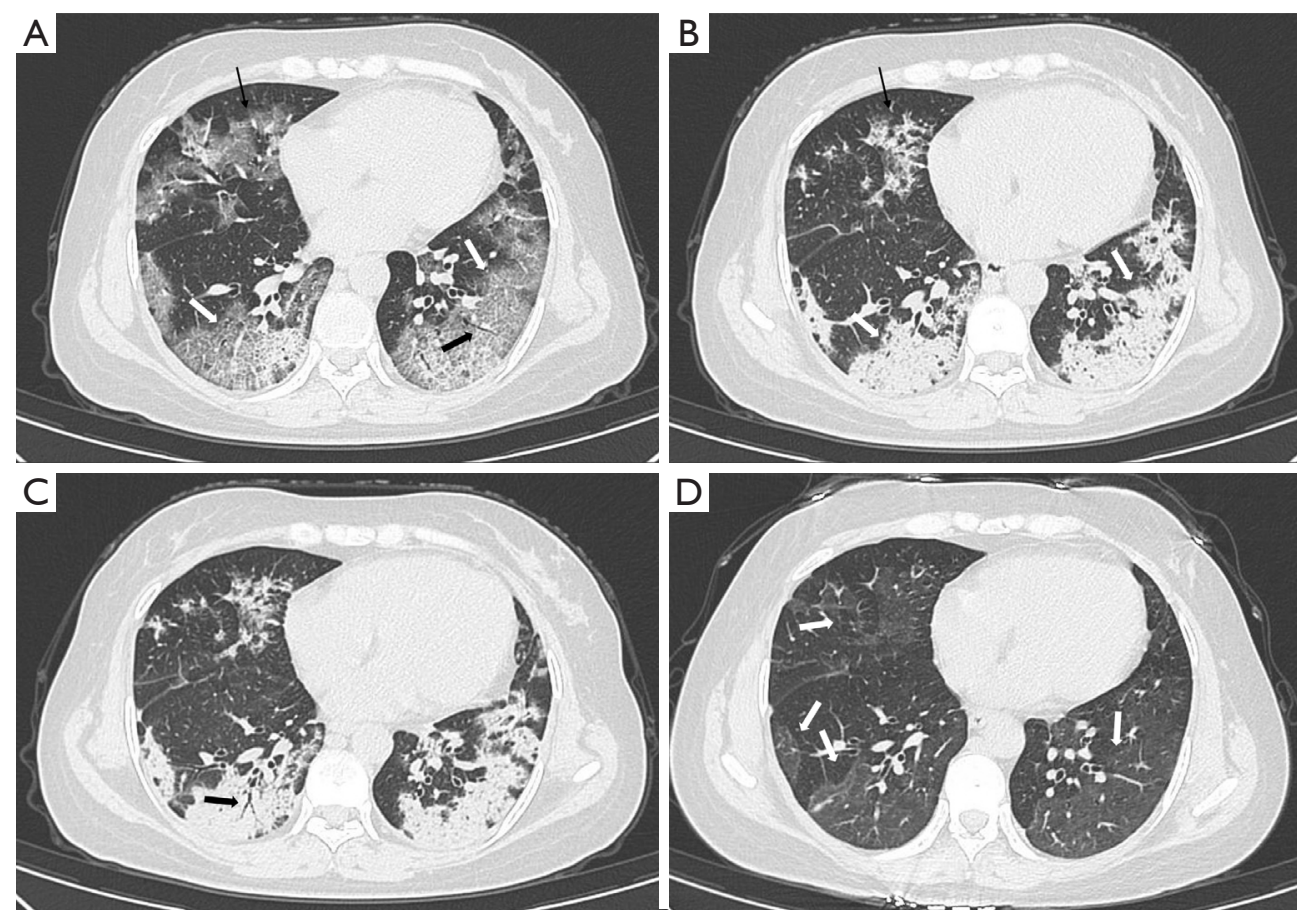

Figure 4 Serial chest CT scans of a 56-year-old male were graded as severe. (A) The scan obtained at the onset of symptoms showed GGO (white arrow) with a mild "crazy-paving" pattern in the right lower lobe (black arrow). (B) The scan obtained 6 days after the onset showed symptoms of increased extension and decreased density of GGO (white arrow) with irregular lines (black arrow). (C) The scan obtained at discharge showed the absorption of previous opacifications and the consolidation of GGO in the left upper lobe (thin arrow). (D) The scan 8 weeks after discharge showed the continuous absorption of previous abnormalities, multiple GGOs (thin arrows) of decreased density, irregular lines (white arrows), and local pleural thickening (black arrows). CT, computerized tomography; GGO, ground-glass opacity.

were not significant $(\mathrm{P}=0.099)$. The $\mathrm{CO}-\mathrm{RADS}$ score was significantly lower both in younger patients $(\mathrm{P}=0.001)$ and patients classified as moderate $(\mathrm{P}=0.005)$. With specific patterns of radiological abnormalities at the first follow-up appointment, GGO ( $\mathrm{P}=0.001)$, air bronchogram $(\mathrm{P}=0.015)$, local pleural thickening $(\mathrm{P}=0.039)$, and an irregular line $(\mathrm{P}=0.005)$ were significantly more common in elder patients than other patients. However, no significant differences were observed between patients classified as moderate and severe/critical (see Table 4).

\section{The dynamics of the lymphocyte subpopulation in convalescent patients}

At the first follow-up appointment, the lymphocyte subpopulation of the 25 patients were evaluated. A total of 10 patients $(10 / 25,40.0 \%)$ showed a decrease in total lymphocytes compared to the normal lower value, and $6(24.0 \%)$ in CD3+ T lymphocytes, 10 in CD4+ T lymphocytes $(10 / 25,40.0 \%), 4(16.0 \%)$ in CD $8+T$ lymphocytes, 3 (12.0\%) in CD19+ B lymphocytes, 5 (20.0\%) in $\mathrm{CD} 56+$ natural killer $(\mathrm{NK})$ lymphocytes. One patient (35 y/o, male, moderate) showed a CD8+T lymphocyte count higher than the normal upper value (see Figure 6).

Fifteen patients attended a second follow-up appointment 16 weeks after discharge. Of these, 7 (46.7\%), 6 (40.0\%), 7 (46.7\%), $1(6.7 \%), 0(0)$, and 1 (6.7\%) continued to show a decreased lymphocyte count compared to the normal lower value for total lymphocyte, CD3+ T lymphocyte, CD4+ T lymphocyte, CD8+ T lymphocyte, CD19+ B lymphocyte, and CD56+ NK lymphocyte, respectively (see Figure 7). The percentage of patients with an abnormal lymphocyte count showed the lymphocyte subpopulation dynamics, and CD4+ showed the minimum degree of lymphopenia recovery (see Figure 8). Also, 3 patients (i.e., Patient No. 1: female, 57 y/o, moderate, Patient No. 5, female, 45 y/o, moderate, and Patient No. 15, male, 22 y/o, moderate) were observed to have progressive lymphopenia at the first follow-up appointment. In 2 of these patients, this was due to a decrease of CD4+, CD8+ T lymphocyte, and CD19+ B 
Table 3 Radiological abnormalities of chest CT scans at different time points

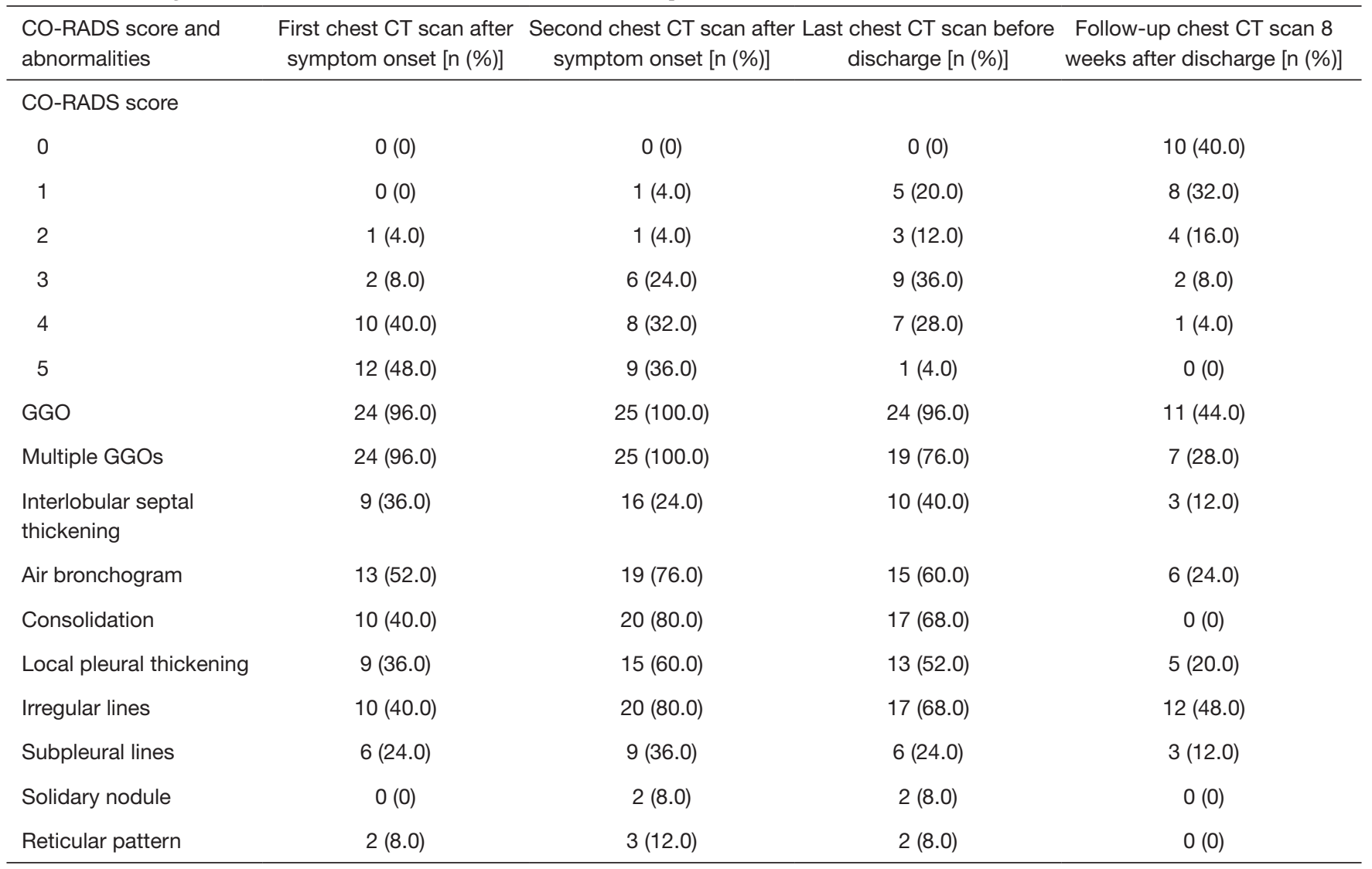

CT, computerized tomography.

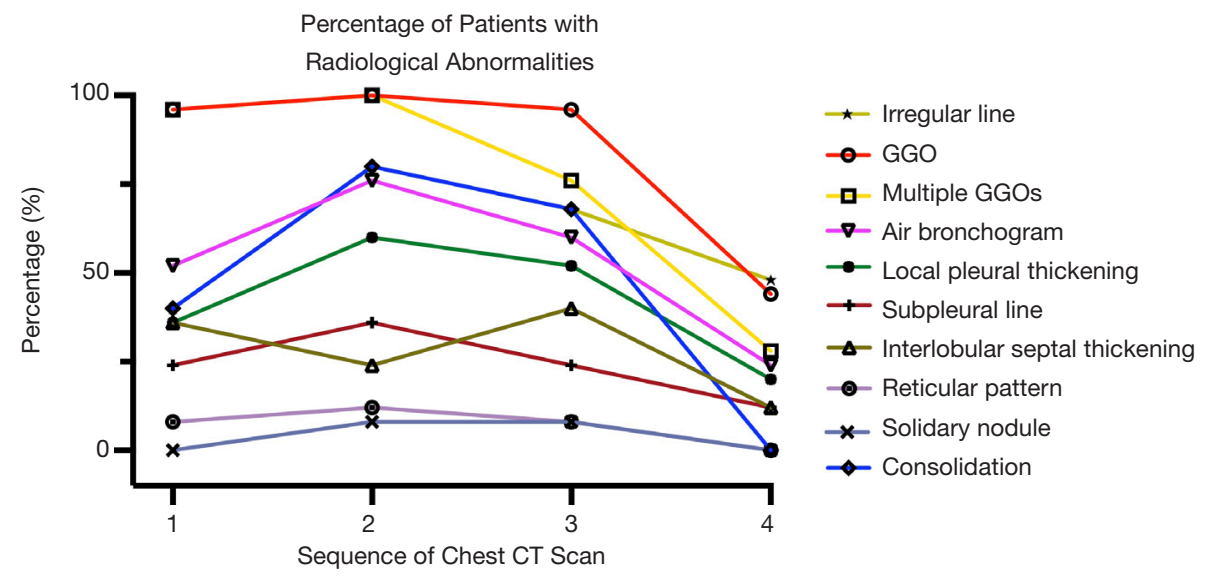

Figure 5 The kinetic of abnormal findings in a chest CT scan at different time points. CT, computerized tomography; GGO, ground-glass opacity.

lymphocyte, while in 1 patient, this was due to a decrease of CD56+ NK lymphocyte (see Figure S1).

Next, we investigated the potential effects of age and disease severity on the recovery of the lymphocyte subpopulation. When patients who were younger and classified as moderate were compared to patients who were older and classified as severe/critical, no significant differences were observed in the percentages of patients 
Table 4 Radiological characteristics between patients with different ages and disease severity

\begin{tabular}{|c|c|c|c|c|c|c|}
\hline $\begin{array}{l}\text { CO-RADS score and } \\
\text { abnormalities }\end{array}$ & $\leq 43$ y/o $(n=12)$ & $>43$ y/o $(n=13)$ & $P$ value ${ }^{\#}$ & Moderate $(n=14)$ & Severe/critical $(n=11)$ & $P$ value \\
\hline Total resolution & $8(66.7 \%)$ & $2,15.4 \%$ & 0.015 & $8(57.1 \%)$ & $2,18.2 \%$ & 0.099 \\
\hline GGO & $1(8.3 \%)$ & $10(76.9 \%)$ & 0.001 & $5(35.7 \%)$ & $6(54.5 \%)$ & 0.435 \\
\hline Air bronchogram & $0(0)$ & $6(46.2 \%)$ & 0.015 & $1(7.1 \%)$ & $5(45.5 \%)$ & 0.056 \\
\hline Consolidation & $0(0)$ & $0(0)$ & - & $0(0)$ & $0(0)$ & - \\
\hline Local pleural thickening & $0(0)$ & $5(38.5 \%)$ & 0.039 & $1(7.1 \%)$ & $4(36.4 \%)$ & 0.133 \\
\hline Solidary nodule & $0(0)$ & $0(0)$ & - & $0(0)$ & $0(0)$ & - \\
\hline Reticular pattern & $0(0)$ & $0(0)$ & - & $0(0)$ & $0(0)$ & - \\
\hline
\end{tabular}

"2-tailed P value by Fisher's exact test. CO-RADS, COVID-19 Reporting and Data System; GGO, ground-glass opacity.

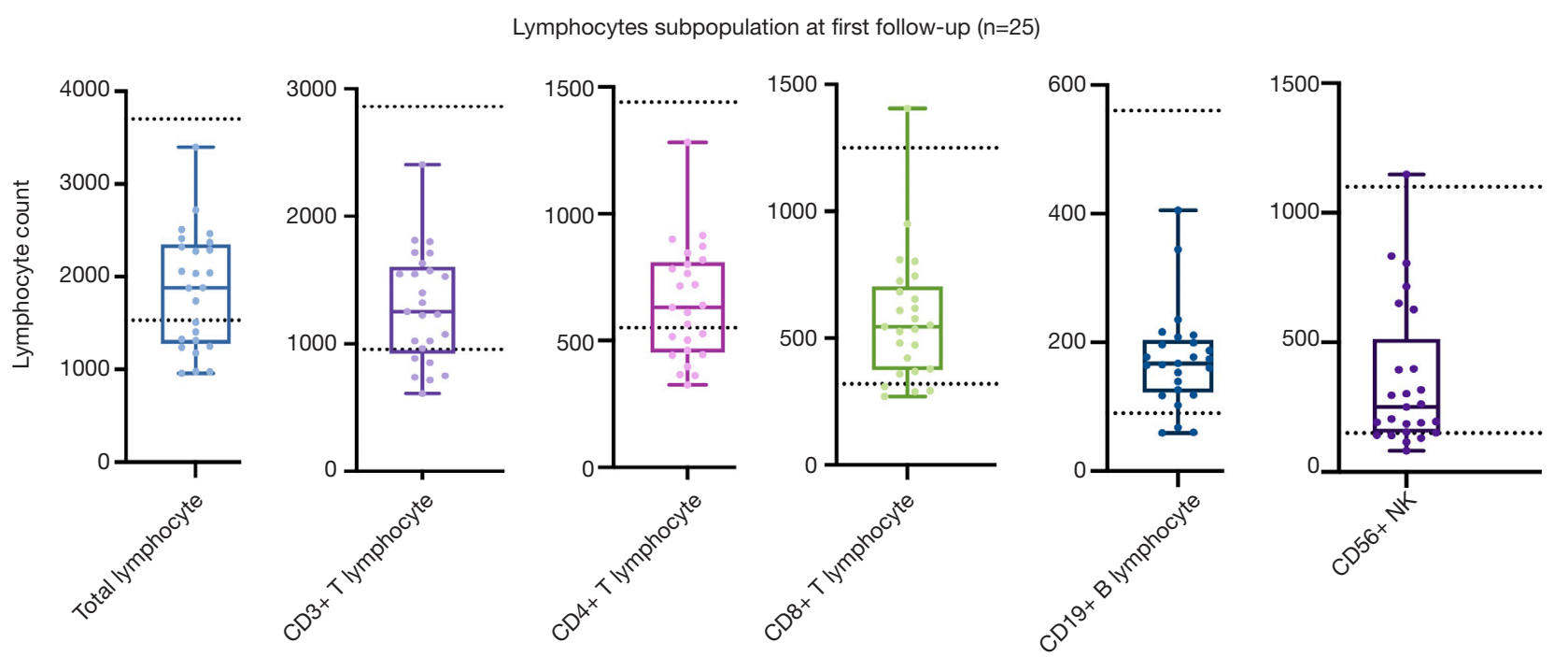

Figure 6 Lymphocyte subpopulations of 25 patients at the first follow-up appointment. The 2 dotted lines indicate the upper and lower values of a normal reference interval.

with abnormalities, regardless of the period following discharge (see Table S1) or the mean value of each subpopulation count (see Figures 9,10).

\section{Dynamics of S-RBD and NP IgG antibody by ELISA}

An ELISA test was conducted to evaluate levels of the IgG antibody. Based on a comparison of the OD450 nm value of different plates, no obvious batch effect was observed between the different ELISA plates (see Figure S2). At the first follow-up appointment, all of the patients were positive for both IgG antibodies. The NP IgG antibody had a median value of $1.46(0.08$ to $4.22,1.80 \pm 1.43)$, and the S-RBD IgG antibody had a median value of 1.50 ( 0.18 
Lymphocytes subpopulation at second follow-up ( $n=15)$
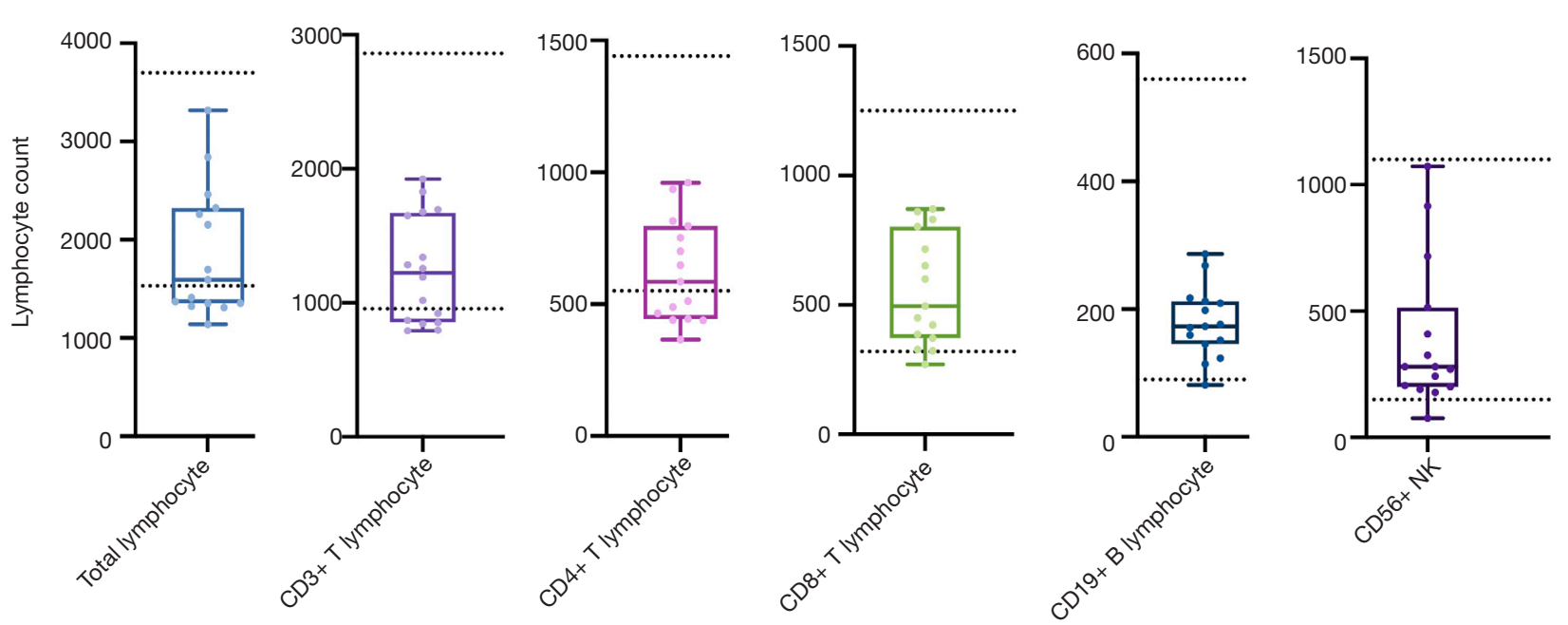

Figure 7 Lymphocyte subpopulations of 15 patients at the second follow-up appointment. The 2 dotted lines indicate the upper and lower values of a normal reference interval.

to $5.06,1.78 \pm 1.14$ ) (see Figure $11 A$ ). At the second followup appointment, a decreased value of 1.30 (0.01 to 3.39, $1.38 \pm 1.13)$ was observed for the NP IgG antibody, and 0.52 $(-0.28$ to $2.54,0.82 \pm 0.95)$ for the S-RBD antibody (see Figure 11B,C).

Of the 15 patients who attended the 2 follow-up appointments, $40 \%(6 / 15)$ and $66.7 \%(10 / 15)$ of patients showed a decrease of over $50.0 \%$ in the NP's levels S-RBD IgG antibodies, respectively. Notably, 0 and 26.7\% (4/15) of patients turned from NP IgG and S-RBD IgG positive to negative, respectively. One patient (male, $19 \mathrm{y} / \mathrm{o}$, moderate) showed an increased NP antibody level at 16 weeks (see Figure $11 B, C$ ). A sample paired analysis with a Wilcoxon test indicated that the S-RBD IgG antibody level declined significantly at 16 weeks compared to that at 8 weeks (44.6\%, P=0.044). Conversely, the NP IgG antibody showed no significant decline between the 2 appointments $(28.1 \%, \mathrm{P}=0.18)$ (see Figure 11B,C).

\section{Discussion}

Following-up with survivors is essential to the overall management of COVID-19. Due to the relatively long follow-up period and the longitudinal design, the current study results provide insights into the radiological and immunological characteristics of COVID-19 patients in the convalescent phase. Specifically, complete radiological recovery was observed in $40.0 \%$ of patients 8 weeks after discharge. Notably, this figure is lower than that of other reports. This may be because other studies had a lower ratio of severe/critical patients $(11,12)$ or a longer followup period than the present study $(9,13)$. In the kinetic analysis of the radiological findings, we observed that GGO or multiple GGOs represented the most common abnormalities at symptom onset and that the percentage of consolidation and air bronchogram increased with disease progression, but that most abnormalities gradually resolved before or after discharge. This was also reflected in the trend of CO-RADS scoring and may represent a common disease course for COVID-19 (12). The predominant patterns of abnormalities 8 weeks after discharge included an irregular line and GGO. Based on pathological observations of remarkable fibrotic lung parenchymal remodeling in patients who died from COVID-19 at autopsy (14), it is speculated that lung fibrosis may be long-term sequelae of COVID-19 patients, however, the irregular lines observed in the current study were mostly sporadic, derived from the absorption of consolidation, and thus differ from real fibrotic lung disease, so further research is still need to determine whether lung fibrosis will be a long-term sequelae of COVID-19 patients, and a combined analysis of pulmonary function and chest CT observations would also be helpful.

GGO remains one of the predominant abnormalities in patients' follow-up chest CT scans; however, the density decreases compared to that observed during hospitalization, 


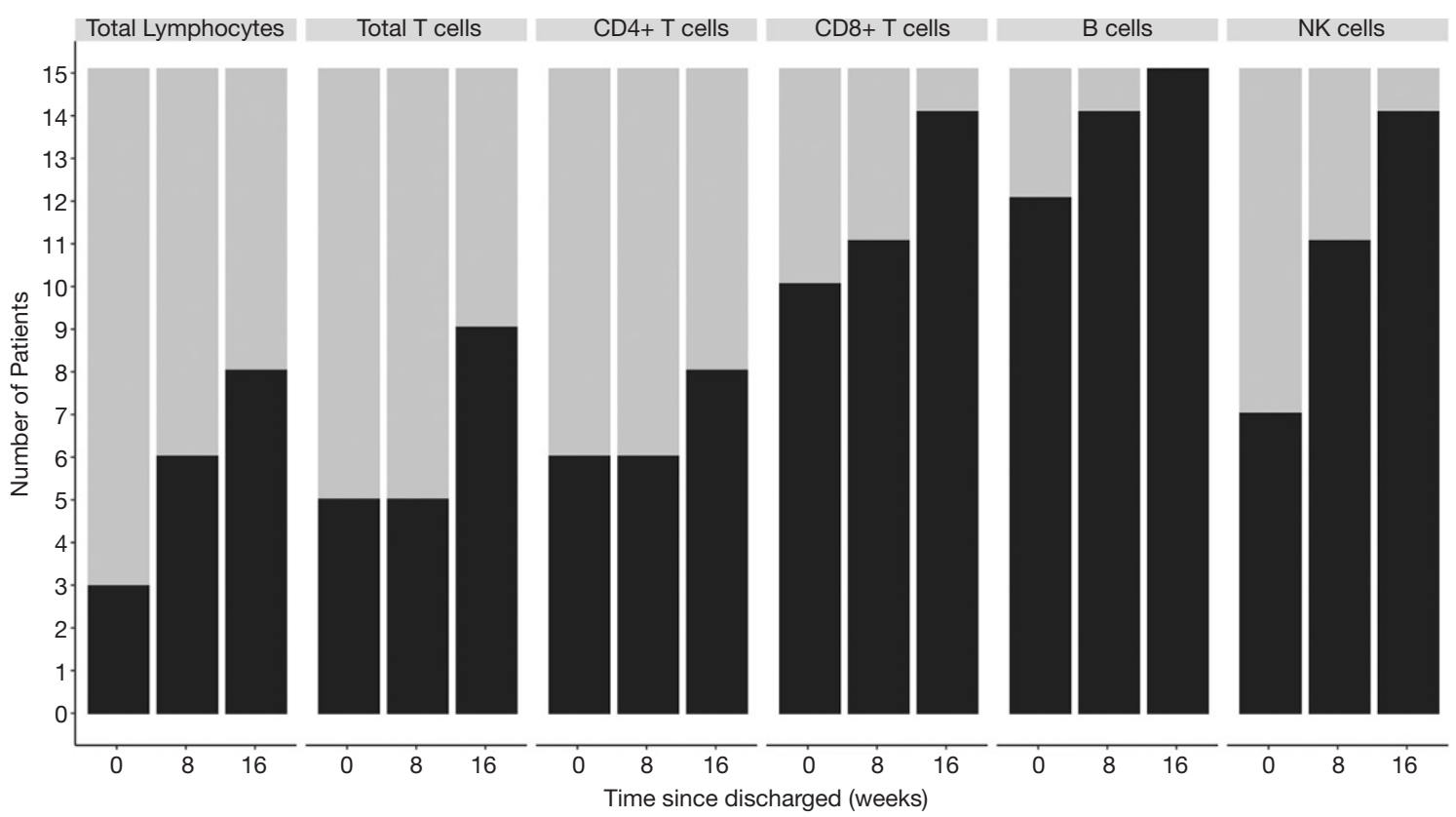

Figure 8 Dynamics of lymphocyte subpopulations in patients who attended 2 follow-up appointments. The grey bar indicates the patients with a decreased absolute number of lymphocytes. The black bar indicates patients with a normal absolute number of lymphocytes.

Total Lymphocyte

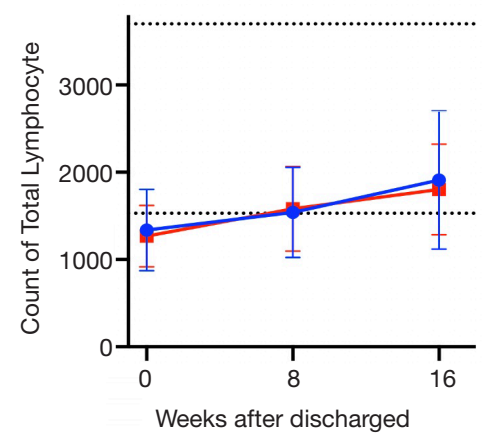

CD8+ Lymphocyte

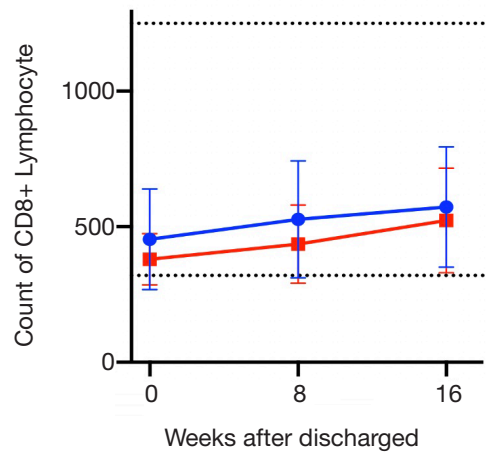

CD3+ T Lymphocyte

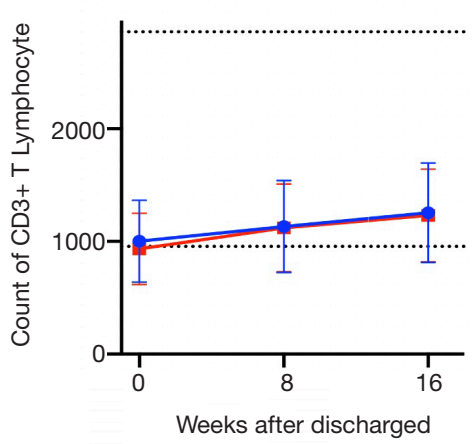

CD56+ NK Cell

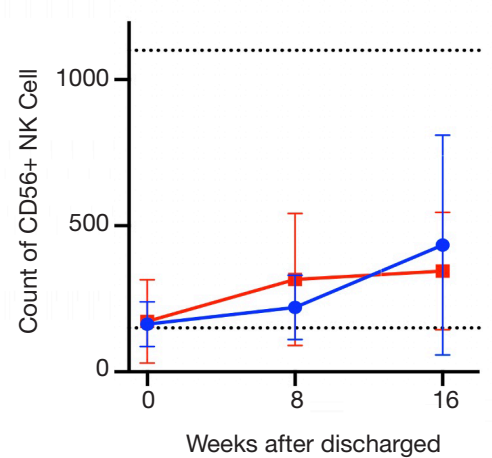

CD4+ Lymphocyte

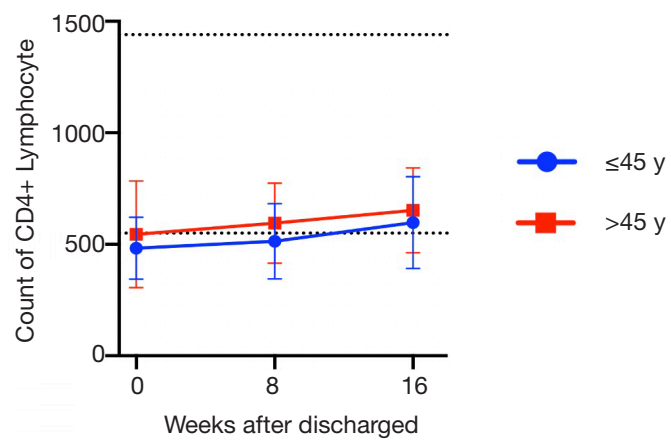

CD19+ B Lymphocyte

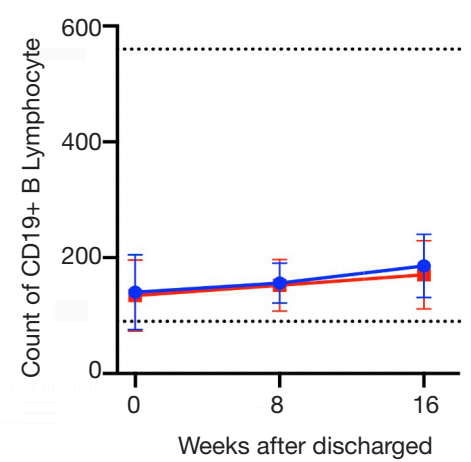

Figure 9 Kinetic analysis of lymphocyte subpopulation in younger and older convalescent patients. Data expressed as mean \pm SD. 
Total Lymphocyte

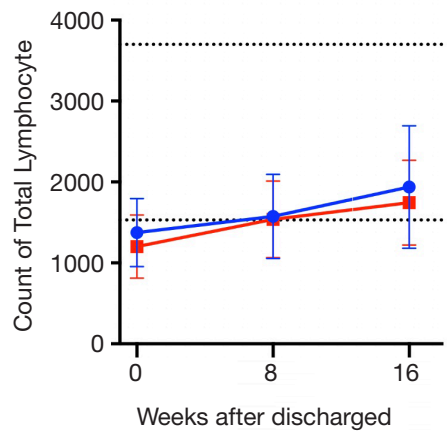

CD8+ Lymphocyte

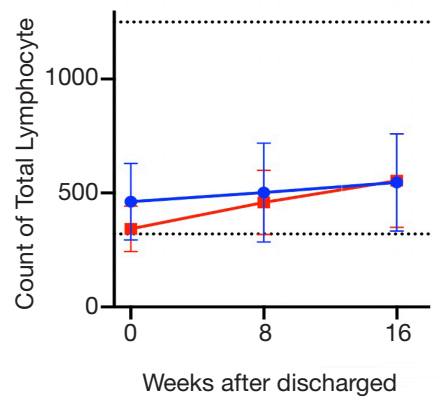

CD3+ T Lymphocyte

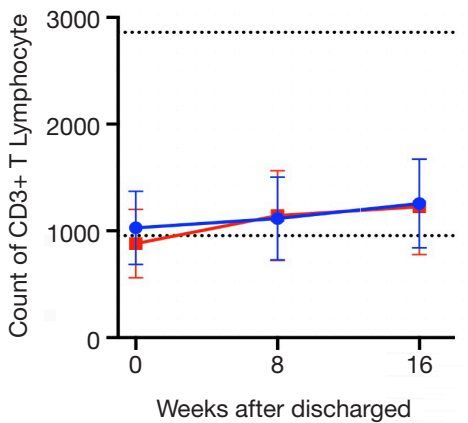

CD56+ NK Cell

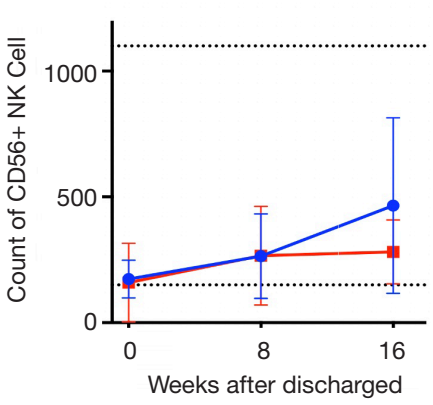

CD4+ Lymphocyte

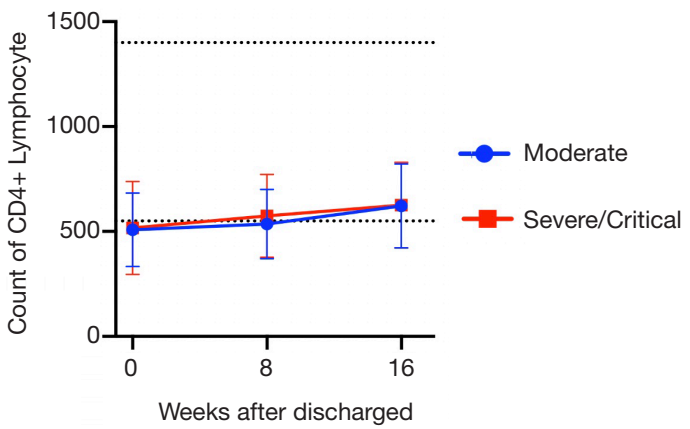

CD19+ B Lymphocyte

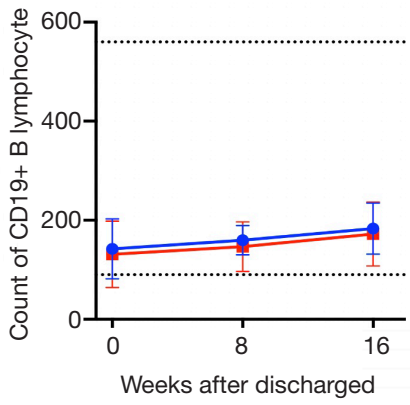

Figure 10 Kinetic analysis of lymphocyte subpopulation in moderate and severe/critical patients. Data expressed as mean \pm SD.
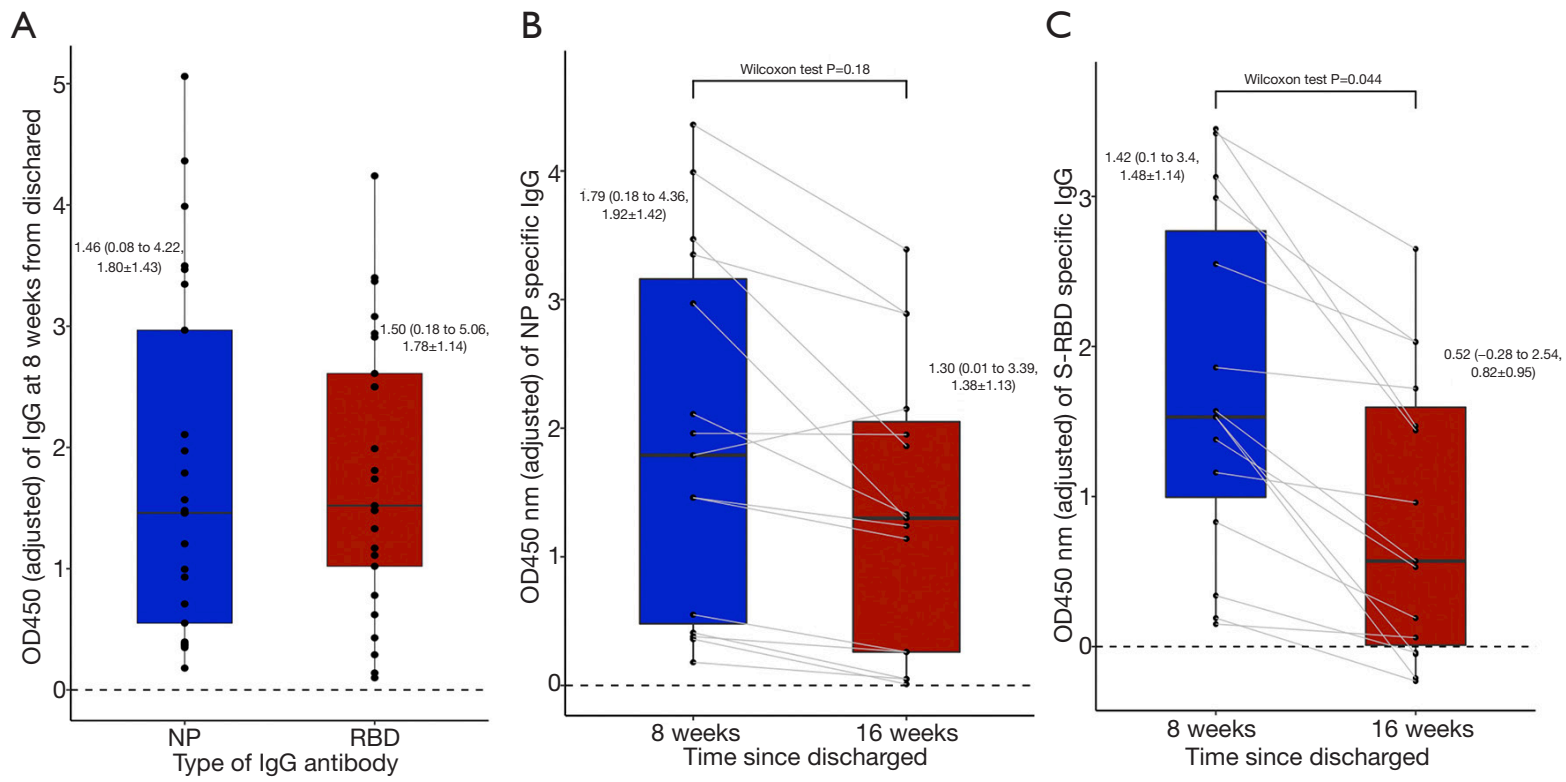

Figure 11 Level of IgG antibodies. (A) Level of the NP- and S-RBD-specific IgG in 25 patients 8 weeks after discharge. (B) Paired analysis of NP antibody level between 8 and 16 weeks after discharge. (C) Paired analysis of S-RBD antibody level between 8 and 16 weeks after discharge. Continuous values were expressed as median (range, mean \pm SD). IgG, immunoglobulin G; NP, Nucleocapsid Protein; S-RBD, S-Receptor binding domain. 
which may be due to the absorption of inflammatory exudate. Other researchers have made similar observations (13). Additionally, older patients showed a significantly lower rate of a complete resolution and a higher rate of several radiological abnormalities after discharge than younger patients; however, this discrepancy was not significant between patients classified as moderate and severe/critical, which suggests that more attention should be paid to older convalescent patients regardless of the disease severity.

Lymphopenia is another key feature of COVID-19. It plays an important role in the disease progression of COVID-19 (15), and to a certain extent, distinguishes COVID-19 from other types of pneumonia (16). In terms of SARS-CoV-1, CD8+ T lymphocytes returned to normal within 2-3 months after the onset of symptoms, and CD4+ T lymphocytes were still lower than those of healthy controls 1 year after that (17). In the present study, the total lymphocyte count was still decreased in $46.7 \%$ of COVID-19 patients 16 weeks after discharge, and the CD4+ T lymphocyte was the most involved lymphocyte subpopulation, which is also the most involved subpopulation in SARS-CoV-1 infection. It has been reported that while the degree of lymphopenia is associated with disease severity during hospitalization, the count of each lymphocyte in patients classified as severe could increase to a comparable level to that of patients classified as mild at day 16 of symptom onset (before discharge) (18). A comparable level of lymphocyte subpopulations was observed regardless of age or severity at different time points after discharge. In addition to the absolute number, other researchers have also found on-going turbulence of lymphocyte function in the phase of early convalescence through the single-cell transcriptome of peripheral blood mononuclear cells (19). The CD4+ T lymphocyte subpopulation is considered one of the major subpopulations responsible for innate immunity and is a major mediator of adaptive immunity (20). The decline of CD4+ T lymphocyte indicates that the immune system has a repressed status and has a higher susceptibility to opportunistic infections $(21,22)$. Although research showed that patients who have recovered from SARS-CoV-1 infection may suffer from a higher infection incidence after discharge in the long-term follow-up (23), there is still no such data regarding to COVID-19, thus, the longterm immunological status of COVID-19 survivors and their susceptibility to other infections need to be examined further.

We also observed that the lymphocyte count of 3 patients at 8 weeks was decreased compared to their discharge results. This may be because their lymphatic systems were impaired and had not yet recovered when discharged (24).

The levels of antibodies against S-RBD and NP were also analyzed. S-RBD and NP IgG antibodies are usually generated 1 week after symptom onset and reach a plateau about 4 weeks after symptom onset (25). One study of 30,082 patients (26) showed that the titer of the neutralizing antibody against the spike protein was stable 3 months after symptom onset but then declined moderately after 5 months. In the current study, similar to the results of another study (27), the level of the S-RBD IgG antibody decreased by $44.6 \%$ from 2 to 4 months after discharge. This raises concerns about whether humoral immunity provides long-lasting protection against SARS-CoV-2. Conversely, the NP IgG antibody only decreased to $28.0 \%$ in the same population, and $93.3 \%$ of patients remained positive for the NP IgG antibody 4 months after discharge.

Due to the S-RBD antibody's capacity to interfere with the entrance of the virus into host cells and thus prevent replication, S-RBD is a widely used target in vaccine development $(28,29)$. Conversely, as NP only exists inside the virus and is wrapped around the ribonucleic acid, the NP antibody is barely capable of blocking the virus's entrance, but could protect the host via the activation of T-cell immunity (30). Further, as the NP's mutation rate is relatively low, NP is another potential target for vaccine development (31). Most vaccines in clinical use provide long-lasting protection, at least in part, through the generation of a pathogen-specific antibody (32). We showed that the NP IgG antibody level was more stable than that of S-RBD 4 months after discharge. This provides more evidence that NP could be used as a potential vaccine target.

This study had several limitations, including a small sample size, a dropout of patients at the second follow-up appointment, and no data on IgG antibody levels during hospitalization. A larger cohort and more comprehensive examinations (e.g., pulmonary functions) would be of great value.

In summary, we performed a longitudinal, observational study of COVID-19 patients in the convalescent phase and assessed their radiological and immunological characteristics. Sixty percent of the patients still showed at least one abnormality on chest CT scans 8 weeks after discharge. The CD4+ T lymphocyte count remained low in about half of the patients 16 weeks after discharge. The level of the S-RBD IgG antibody declined more dramatically 
than that of NP. These results could help us understand the health consequences of COVID-19 and assist in developing vaccines.

\section{Acknowledgments}

We would like to thank Shi Dp and Liu Hm from the Department of Radiology of Henan Provincial People's Hospital for interpreting the chest CT data.

Funding: This work is funded by the Emergency Research Project of Henan Science and Technology Department (No. 201100310700).

\section{Footnote}

Reporting Checklist: The authors have completed the STROBE reporting checklist. Available at http://dx.doi. org/10.21037/jtd-20-3011

Data Sharing Statement: Available at http://dx.doi. org/10.21037/jtd-20-3011

Peer Review File: Available at http://dx.doi.org/10.21037/jtd20-3011

Conflicts of Interest: All authors have completed the ICMJE uniform disclosure form (available at http://dx.doi. org/10.21037/jtd-20-3011). The authors have no conflicts of interest to declare.

Ethical Statement: The authors are accountable for all aspects of the work in ensuring that questions related to the accuracy or integrity of any part of the work are appropriately investigated and resolved. The study was conducted in accordance with the Declaration of Helsinki (as revised in 2013). The Ethics Committee of Henan Provincial People's Hospital approved this research study (2020 Ethical Approval No. 68), and the informed consent of all patients was obtained.

Open Access Statement: This is an Open Access article distributed in accordance with the Creative Commons Attribution-NonCommercial-NoDerivs 4.0 International License (CC BY-NC-ND 4.0), which permits the noncommercial replication and distribution of the article with the strict proviso that no changes or edits are made and the original work is properly cited (including links to both the formal publication through the relevant DOI and the license).
See: https://creativecommons.org/licenses/by-nc-nd/4.0/.

\section{References}

1. Scudellari M. How the pandemic might play out in 2021 and beyond. Nature 2020;584:22-5.

2. World Health Organization. Coronavirus disease (COVID-19) weekly epidemio-logical update and weekly operational update. Available online: https://www.who.int/ emergencies/diseases/novel-coronavirus-2019/situationreports

3. Chen N, Zhou M, Dong X, et al. Epidemiological and clinical characteristics of 99 cases of 2019 novel coronavirus pneumonia in Wuhan, China: a descriptive study. Lancet 2020;395:507-13.

4. Guan WJ, Ni ZY, Hu Y, et al. Clinical Characteristics of Coronavirus Disease 2019 in China. N Engl J Med 2020;382:1708-20.

5. Wu Z, McGoogan JM. Characteristics of and Important Lessons from The Corona-virus Disease 2019 (Covid-19) Outbreak in China: Summary of a report of 72314 cases from the Chinese Center for Disease Control and Prevention. JAMA 2020;323:1239-42.

6. Grasselli G, Zangrillo A, Zanella A, et al. Baseline characteristics and outcomes of 1591 patients infected with SARS-CoV-2 admitted to ICUs of the Lombardy Region, Italy. JAMA 2020;323:1574-81.

7. Blanco MD, Nilsson PBE, Liu WC, et al. Imbalanced Host Response to SARS-CoV-2 Drives Development of COVID-19. Cell 2020;181:1036-45.e9.

8. Commission CNH. New Coronavirus Pneumonial Diagnosis and Treatment Pro-gram. 5th ed. (2020). Available online: http://www.nhc.gov.cn/xcs/zhengcwj/202 002/3b09b894ac9b4204a79db5b8912d(4440).shtml

9. Huang C, Huang L, Wang Y, et al. 6-month consequences of COVID-19 in patients discharged from hospital: a cohort study. Lancet 2021;397:220-32.

10. Dao TL, Hoang VT, Gautret $P$, et al. Recurrence of SARS-CoV-2 viral RNA in recovered COVID-19 patients: a narrative review. Eur J Clin Microbiol Infect Dis 2021;40:13-25.

11. Liu D, Zhang W, Pan F, et al. The pulmonary sequalae in discharged patients with COVID-19: a short-term observational study. Respir Res 2020;21:125.

12. Liu C, Ye L, Xia RK, et al. Chest Computed Tomography and Clinical Follow-Up of Discharged Patients with COVID-19 in Wenzhou City, Zhejiang, China. Ann Am Thorac Soc 2020;17:1231-7. 
13. Han X, Fan Y, Alwalid O, et al. Six-month Follow-up Chest CT Findings after Severe COVID-19 Pneumonia. Radiology 2021;299:E177-86.

14. Grillo F, Barisione E, Ball L, et al. Lung fibrosis: an undervalued finding in COVID-19 pathological series. Lancet Infect Dis 2021;21:e72.

15. Wang J, Jiang M, Chen X, et al. Cytokine storm and leukocyte changes in mild versus severe SARS-CoV-2 infection: Review of 3939 COVID-19 patients in China and emerging pathogenesis and therapy concepts. J Leukoc Biol 2020;108:17-41.

16. Paliogiannis P, Zinellu A, Scano V, et al. Laboratory test alterations in patients with COVID-19 and non COVID-19 interstitial pneumonia: a preliminary report. J Infect Dev Ctries 2020;14:685-90.

17. Xie J, Fan HW, Li TS, et al. Dynamic changes of T lymphocyte subsets in the long-term follow-up of severe acute respiratory syndrome patients. Zhongguo Yi Xue Ke Xue Yuan Xue Bao 2006;28:253-5.

18. Liu J, Li S, Liu J, et al. Longitudinal characteristics of lymphocyte responses and cytokine profiles in the peripheral blood of SARS-CoV-2 infected patients. EBioMedicine 2020;55:102763.

19. Wen $W$, Su W, Tang H, et al. Immune cell profiling of COVID-19 patients in the recovery stage by single-cell sequencing. Cell Discov 2020;6:31.

20. Vesely MD, Kershaw MH, Schreiber RD, et al. Natural innate and adaptive immunity to cancer. Annu Rev Immunol 2011;29:235-71.

21. Saharia KK, Koup RA. T cell susceptibility to HIV influences outcome of opportunistic infections. Cell 2013;155:505-14.

22. Shavit R, Maoz-Segal R, Prizinsky S, et al. Immunodeficiency (CVID and CD4 lymphopenia) is associated with a high risk of malignancy among adults with primary immune deficiency. Clin Exp Immunol

Cite this article as: Wang Z, Yang L, Chen Y, Xu Z, Wang H, Zhang X. A longitudinal follow-up of COVID-19 patients in the convalescent phase showed recovery in radiological results, the dynamics of lymphocytes, and a decrease in the level of IgG antibody: a single-centre, observational study. J Thorac Dis 2021;13(5):2986-3000. doi: 10.21037/jtd-20-3011
2021;204:251-7.

23. Wu Q, Zhou L, Sun X, et al. Altered lipid metabolism in recovered SARS patients twelve years after infection. Sci Rep 2017;7:9110.

24. China National Health Commission. Chinese clinical guidance for COVID-19 pneumonia diagnosis and treatment (7th Edition). Available online: http://kjfy. meetingchina.org/msite/news/show/cn/3337.html (accessed Dec 10, 2020).

25. Ren L, Fan G, Wu W, et al. Antibody responses and clinical outcomes in adults hospitalized with severe COVID-19: a post hoc analysis of LOTUS China trial. Clin Infect Dis 2021;72:e545-e551.

26. Wajnberg A, Amanat F, Firpo A, et al. Robust neutralizing antibodies to SARS-CoV-2 infection persist for months. Science 2020;370:1227-30.

27. Ibarrondo FJ, Fulcher JA, Goodman-Meza D, et al. Rapid decay of anti-SARS-COV-2 antibodies in persons with mild COVID-19. N Engl J Med 2020;383:1085-7.

28. Tai $W$, Zhang X, Drelich A, et al. A novel receptor-binding domain (RBD)-based mRNA vaccine against SARSCoV-2. Cell Res 2020;30:932-5.

29. Yang J, Wang $W$, Chen $Z$, et al. A vaccine targeting the $\mathrm{RBD}$ of the $\mathrm{S}$ protein of SARS-CoV-2 induces protective immunity. Nature 2020;586:572-7.

30. Caddy SL, Vaysburd M, Papa G, et al. Viral nucleoprotein antibodies activate TRIM21 and induce T cell immunity. EMBO J 2021;40:e106228.

31. Dutta NK, Mazumdar K, Gordy JT. The Nucleocapsid Protein of SARS-CoV-2: a Target for Vaccine Development. J Virol 2020;94:e00647-20.

32. Davis CW, Jackson KJL, McCausland MM, et al. Influenza vaccine-induced human bone marrow plasma cells decline within a year after vaccination. Science 2020;370:237-41.

(English Language Editors: L. Huleatt and J. Chapnick) 

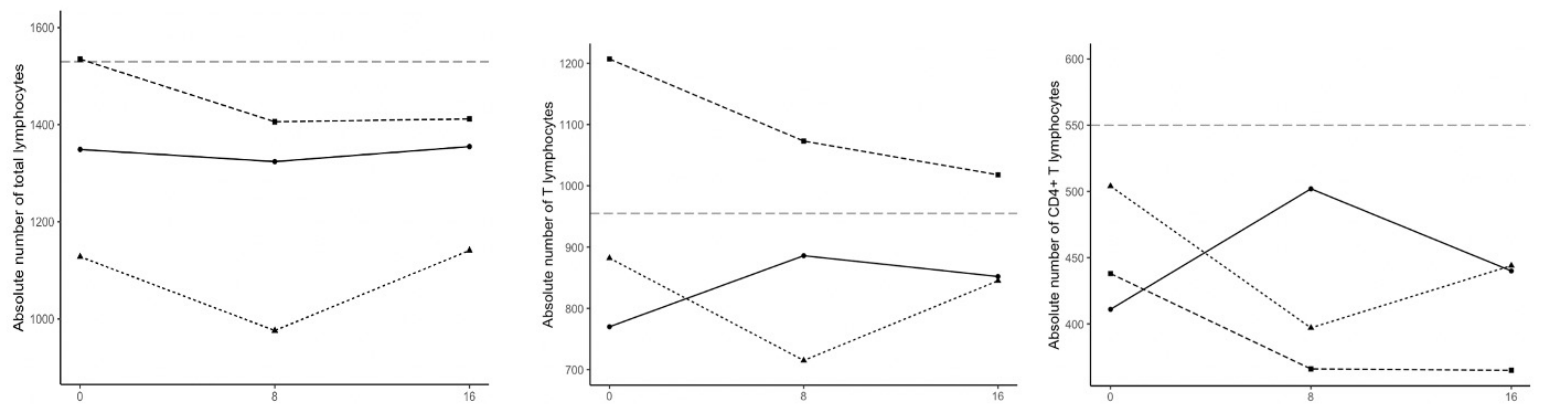

Patient
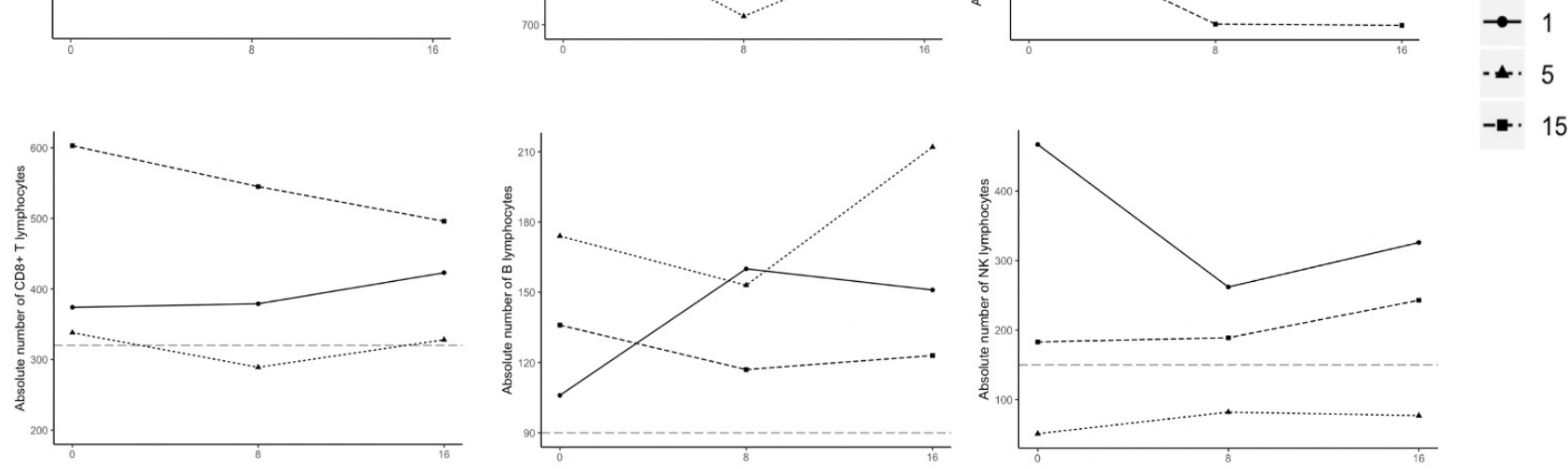

Time Since Discharged(weeks)

Figure S1 Dynamics of lymphocyte subpopulations in 3 patients who experienced progressive lymphopenia after discharge. The gray dotted line indicates the lower values of the normal reference interval. 
Table S1 Number and fraction of patients with a decreased level of lymphocyte subpopulation

\begin{tabular}{|c|c|c|c|c|c|c|c|}
\hline \multicolumn{8}{|c|}{ Decreased Compared to Normal Lower Value (n/total, \%) } \\
\hline $\begin{array}{l}\text { Lymphocyte } \\
\text { subpopulation }\end{array}$ & $\begin{array}{c}\text { Weeks after } \\
\text { discharge }\end{array}$ & $\begin{array}{c}\leq 45 \mathrm{y} / \mathrm{o} \\
(\mathrm{n}=8)\end{array}$ & $\begin{array}{c}>45 \text { y/o } \\
(n=7)\end{array}$ & $P$-value ${ }^{\#}$ & $\begin{array}{l}\text { Moderate } \\
\quad(n=9)\end{array}$ & $\begin{array}{l}\text { Severe/Critical } \\
\qquad(n=6)\end{array}$ & P-value \\
\hline \multirow{2}{*}{ Total Lymphocytes } & 8 & $5,62.5 \%$ & $4,57.1 \%$ & 1.000 & $5,55.6 \%$ & $4,66.7 \%$ & 1.000 \\
\hline & 16 & $4,50.0 \%$ & $3,42.9 \%$ & 1.000 & $4,44.4 \%$ & $3,50.0 \%$ & 1.000 \\
\hline \multirow{2}{*}{ Total T cell } & 8 & $5,62.5 \%$ & $5,57.1 \%$ & 1.000 & $5,33.3 \%$ & $5,50.0 \%$ & 0.580 \\
\hline & 16 & $3,37.5 \%$ & $3,42.9 \%$ & 1.000 & $3,33.3 \%$ & $3,50.0 \%$ & 0.622 \\
\hline CD4+ T cell & 0 & $6,75.0 \%$ & $4,57.1 \%$ & 0.608 & $6,66.7 \%$ & $4,66.7 \%$ & 1.000 \\
\hline \multirow{2}{*}{ CD8+ T cell } & 8 & $2,25.0 \%$ & $2,28.6 \%$ & 1.000 & $1,11.1 \%$ & $3,50.0 \%$ & 0.235 \\
\hline & 16 & 0,0 & $1,14.3 \%$ & 0.467 & 0,0 & $1,16.7 \%$ & 0.400 \\
\hline \multirow[t]{3}{*}{ B cell } & 0 & $2,25.0 \%$ & $1,14.3 \%$ & 1.000 & $2,22.2 \%$ & $1,16.7 \%$ & 1.000 \\
\hline & 8 & 0,0 & $1,14.3 \%$ & 0.467 & 0,0 & $1,16.7 \%$ & 0.400 \\
\hline & 16 & 0,0 & 0,0 & - & 0,0 & 0,0 & - \\
\hline \multirow[t]{2}{*}{ NK cell } & 0 & $4,50.0 \%$ & $4,57.1 \%$ & 1.000 & $4,44.4 \%$ & $4,66.7 \%$ & 0.608 \\
\hline & 8 & $2,25.0 \%$ & $2,28.6 \%$ & 1.000 & $3,33.3 \%$ & $1,16.7 \%$ & 0.604 \\
\hline
\end{tabular}

\footnotetext{
\#2-tailed P-value by Fisher's exact test.
}

\section{OD450nm of Blank Control Across Different ELISA Plates}

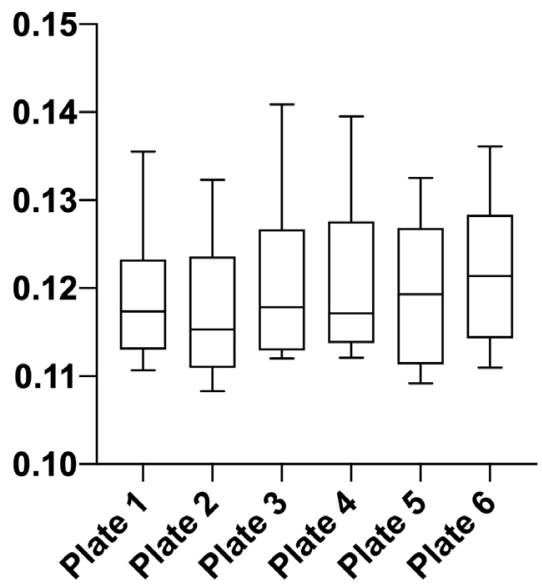

Figure S2 Mean OD450 nm value of blank controls between different ELISA plates. 